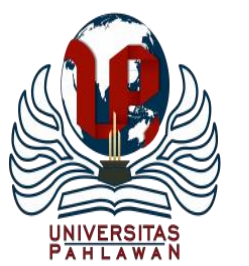

Jurnal Abdidas Volume 2 Nomor 1 Tahun 2021 Halaman 59-68

JURNAL ABDIDAS

http://abdidas.org/index.php/abdidas

\title{
Pendampingan Analisis Usaha Pembuatan Abon Rebung di UKM "Raja Abon Makmur Lestari” Kelurahan Air Kepala Tujuh Kota Pangkal Pinang
}

\author{
Yulia $^{凶}$ \\ Universitas Bangka Belitung, Indonesia \\ E-mail : yuliaubb@gmail.com
}

\begin{abstract}
Abstrak
Pada umumnya di Indonesia tanaman hortikultura banyak dijadikan sebagai makanan terutama pada sayurmayur dan buah-buahan, sedangkan rempah-rempah dijadikan sebagai bumbu masakan. Salah satu usaha tersebut yaitu di produksi oleh "Raja Abon Makmur Lestari" berbahan baku dari tanaman yang bernama abon rebung. Tanaman rebung adalah tunas bambu yang masih sangat muda yang tumbuh sekitar $15-25 \mathrm{~cm}$ di sekitaran tanaman bambu yang mudah didapatkan untuk dijadikan bahan sayur-mayur atau dijadikan sebagai produk olahan. Tujuan kegiatan pengabdian ini adalah mendampingi usaha mandiri Raja Abon Makmur Lestari dalam praktek pembuatan abon rebung dan membuat analisis usahanya. Metode pelaksanaan dilakukan dengan persiapan program, sosialisasi usaha abon rebung, serta pendampingan pembuatan analisis usaha. Metode pengumpulan data dengan wawancara dan angket. Analisis yang dilakukan dengan deskriptif kualitatif. Hasil kegiatan pendampingan adalah pemilik usaha abon rebung sudah bisa mengolah produksi produk abon rebung serta terampil dan kreatif dalam membuat analisis usahanya.
\end{abstract}

Kata kunci : abon rebung, analisis usaha, pendampingan

\begin{abstract}
In general, in Indonesia horticultural crops are widely used as food, especially in vegetables and fruits, while spices are used as seasonings. One such business is in production by Raja Abon Makmur Lestari" prosperous sustainable made from raw plants called abon bamboo shoots. Bamboo shoots are bamboo shoots that are still very young that grow about $15-25 \mathrm{~cm}$ around bamboo plants that are easy to get to be used as vegetable ingredients or used as processed products. The purpose of this devotion activity is to accompany the independent efforts of the "Raja Abon Makmur Lestari" in the practice of making bamboo shoots abon and making business analysis. Implementation method is carried out by program preparation, socialization of bamboo shoots business, as well as assistance in making business analysis. Data collection methods with interviews and questionnaires. The analysis is done descriptive qualitatively. The result of mentoring activities is the owner of abon bamboo shoots business can already process the production of bamboo shoots abon products and skilled and creative in making business analysis.
\end{abstract}

Keywords: bamboo shoots, business analysis, mentoring

Copyright (c) 2021 Yulia

$\triangle$ Corresponding author

Address : Universitas Bangka Belitung

Email : yuliaubb@gmail.com

DOI : https://doi.org/10.31004/abdidas.v2i1.209

ISSN 2721- 9224 (Media Cetak)

ISSN 2721- 9216 (Media Online) 


\section{PENDAHULUAN}

Pada umumnya di Indonesia tanaman hortikultura banyak dijadikan sebagai makanan terutama pada sayur-mayur dan buah-buahan, sedangkan rempah-rempah di jadikan sebagai bumbu masakan (Jaka S Sumardjo, 2004). Pada jenis sayur-mayur sendiri cukup banyak di kenal oleh masyarakat Indonesia. (Wijatno, 2009) mengatakan ada yang dijadikan sayuran masak sebagai lauk-pauk dirumah atau sebagai produk olahan yang memiliki nilai jual tinggi untuk peluang usaha.

Tanaman rebung adalah tunas bambu yang masih sangat muda yang tumbuh sekitar $15-25 \mathrm{~cm}$ disekitaran tanaman bambu yang mudah didapatkan untuk dijadikan bahan sayur-mayur atau dijadikan sebagai produk olahan (Arda et al., 2016). Pemanfaatan rebung sendiri pada umumnya dimasak dengan cara diiris tipis dan dicampur dengan kuah sayur-mayur, atau juga bisa sebagai bahan tambahan untuk isi makanan ringan seperti lumpia dan sejenisnya (Howard Patty et al., 2014). Rebung yang memiliki tekstur sedikit lembut dan renyah membuat rebung menjadi mudah untuk diolah juga dikonsumsi (Rachmadi, 2011).

Sebagai salah satu komoditas yang berpeluang secara ekonomis, rebung dapat diusahakan sebagai produk olahan yang berpotensi dalam pengembangan agribisnis (Yulia et al., 2019). Agribisnis di Indonesia termasuk salah satunya pengolahan rebung, berkaitan dengan perkembangan pertanian pada pertanian tradisional, petani mengusahakan suatu komoditas hanya untuk keperluan konsumsi keluarga. Sejalan dengan perkembangannya (Yulia et al., 2019).
Usaha-usaha untuk membudiyakan tanaman, hewan dan ikan mulai menggunakan sarana sendiri maupun untuk di pasarkan.

Abon yang terbuat dari buah-buahan yang berserat tinggi relatif mudah didapatkan dan harga bahan baku yang relatif lebih murah dari pada harga bahan baku daging seperti sapi dan ayam. Seperti halnya abon yang terbuat dari rebung, selain harga yang murah dipasaran, rebung sendiri mudah didapatkan, Namun selain memiliki kandungan serat yang tinggi rebung juga memiliki kadar air yang cukup tinggi juga yang berkisaran 90,6\%. Maka dari itu, untuk menjadikan rebung sebagai bahan baku pembuatan abon membutuhkan jumlah rebung yang tergolong sangat banyak, untuk $1 \mathrm{~kg}$ abon rebung dibutuhkan 10 kg Rebung Bambu.

Abon yang sebelumnya sudah banyak dikenal oleh masyarakat luas akan lebih mempermudah dan membantu pengembangan rumah produksi abon saat ini. Dan abon rebung yang merupakan sebuah inovasi atas pemanfaatan bahan yang kurang diminati ini akan menjadi sangat diminati oleh masyarakat, selain harga yang murah untuk sebuah makanan yang diminati didukung pula oleh sifat masyarakat yang relatif ingin mencoba sesuatu yang baru. Pemanfaatan rebung menjadi abon buah memiliki nilai ekonomis, oleh karena itu akan sangat menguntungkan bila dapat memanfaatkan rebung menjadi suatu produk yang mempunyai nilai jual tinggi dan nilai guna dengan mengubahnya menjadi abon rebung, yang pada umumnya rebung hanya dijadikan sebagai sayuran. Pembuatan abon rebung adalah salah satu kegiatan pengolahan 
rebung, dimana rebung memiliki harga yang relatif terjangkau dan mudah didapat. Hal ini juga akan berpengaruh pada pengembangan usaha yang disebabkan oleh permintaan masyarakat terhadap abon rebung sendiri.

Dilihat dari aspek ekonomis bisnis usaha abon telur sangat menguntungkan karena produk tersebut sangat mudah dibawa kemana saja karena kemasan yang sangat ekonomis (Yulia et al., 2019). Kemudian produk abon juga bisa menjadi lauk makan yang sangat menggiurkan dan bisa juga dijadikan cemilan untuk bersantai, sama seperti jenis abon pada umumnya. Tujuan kegiatan pengabdian ini adalah mendampingi usaha mandiri yang dilakukan oleh pelaku usaha raja abon makmur lestari dalam praktek pembuatan abon rebung dan membuat analisis perhitungan usahanya.

\section{METODE}

Pengabdian ini dilaksanakan pada bulan Agustus 2020 sampai dengan Oktober 2020. Bertempat di usaha pembuatan abon rebung di Usaha Kecil Menengah (UKM) "Raja Abon Makmur Lestari” Kelurahan Air Kepala Tujuh Kota Pangkal Pinang.

\section{Bahan dan Alat yang Digunakan}

Bahan baku yang digunakan dalam proses produksi pembuatan abon rebung sebanyak $1 \mathrm{~kg}$ (satu kali produksi):

1. $10 \mathrm{~kg}$ Rebung Bambu

Rebung bambu yang digunakan sebaiknya belum terlalu tua dan tidak terlalu muda karena akan mempengaruhi tekstur gurih yang dimiliki oleh rebung. Ukuran rebung yang digunakan relatif karena ukuran rebung tidak mempengaruhi hasil produksinya.

2. 100 gram cabai merah

Cabai merah digunakan sebagai bahan pemberi rasa pedas pada pembuatan abon rebung.

3. $600 \mathrm{ml}$ santan kelapa

Santan kelapa digunakan sebagai bahan pengental pada pembuatan abon.

4. 100 gram laos

Laos mengandung senyawa flavonoid yang terdapat pada minyak astiri yang ada di rimpangnya, senyawa flavonoid ini berfungsin sebagai antioksidan pada proses pembuatan makanan kering.

5. 50 gram bawang merah

Bawang merah berfungsi sebagai pemberi aroma khas bumbu alami dalam pembuatan abon rebung. Aroma yang dihasilkan oleh bawang merah disebabkan kerusakan sel pada bawang merah yang mengeluarkan senyawa sulfur yang akan menyebabkan aroma khas.

6. 50 gram bawang putih

Bawang putih berfungsi sebagai pemberi aroma dan memberikan rasa gurih dalam pembuatan abon rebung.

7. 5 lembar daun salam

Daun salam digunakan untuk memperkuat citarasa dan memberikan aroma pada pembuatan abon.

8. 2 batang serai

Serai digunakan untuk memberikan aroma harum pada pembuatan abon rebung saat penggorengan. 
9. 100 gram gula pasir

Gula pasir digunakan sebagai pemberi rasa manis dan guri pada proses pembuatan abon rebung.

10.5 gram asam jawa

Asam jawa digunakan sebagai pemberi warna gelap pada proses pembuatan abon rebung.

\section{Garam}

Garam secukupnya sebagai pemberi rasa agar lebih gurih. Rasa asin yang terkandung pada garam menyebabkan makanan kering terasa lebih gurih.

\section{3 liter minyak goreng}

Minyak goreng digunakan dalam proses penggorengang untuk melekatkan dan mencampurkan bahan pada abon rebung.

Berikut alat yang digunakan dalam proses produksi pembuatan abon rebung :

1. Pisau

Digunakan untuk membersihkan rebung yang berwarna coklat karena proses respirasi. Pembersihan rebung ini dilakukan sebelum pencucian rebung dan pemarutan rebung.

2. Blender

Blender digunakan untuk menghaluskan bumbu yang akan akan dicampurkan pada bahan baku pembuatan abon rebung.

3. Baskom

Baskom digunakan sebagai wadah tempat meletakan rebung sebelum dan sesudah dibersihkan dan tempat pencucian rebung yang sudah dibersihkan.

4. Mesin Pemarut
Mesin pemarut yang digunakan berbahan bakar bensin yang digunakan untuk memarut rebung yang telah dicuci bersih.

5. Kompor Gas

Kompor gas digunakan untuk menggoreng semua bahan pembuatan abon rebung.

6. Tabung Gas

Tabung gas digunakan sebagai bahan bakar pemasok untuk menyalakan api pada kompor gas.

7. Wajan

Wajan digunakan sebagai wadah untuk penggorengan bahan baku pembuatan abon rebung. Wajan yang digunakan adalah wajah yang berukuran besar.

8. Spatula

Spatula digunaka sebagai alat bantu pengadung bahan baku pembuatan abon rebung yang sedang dalam proses penggorengan hingga selesai.

9. Kain Bersih

Kain bersih digunakan sebagai alat untuk meletakkan rebung yang telah parut untuk disaring airnya.

10.Pres Hydraulic

Pres Hydraulic digunakan untuk memeras kandungan air yang ada pada rebung setelah diparut. Alat ini digunakan dengan cara manual yaitu diputar.

\section{Penyaring minyak (Spinner)}

Penyaring minyak (Spinner) digunakan untuk menyaring minyak yang terkandung pada abon rebung yang sudah selesai melalui proses penggorengan hingga benar-benar kering. 


\section{Timbangan}

Timbangan digunakan untuk mengukur berat bersih pada abon saat proses pengemasan. Timbangan yang digunakan adalah jenis timbangan analog.

\section{Sealer}

Sealer adalah alat pres untuk menyegel kemasan platik yang digunakan untuk pengemasan abon agar tidak adanya udara yang masuk kedalam kemasan abon.

\section{Bentuk kegiatan}

Bentuk kegiatan yang dilakukan meliputi persiapan proses pembuatan, pendampingan praktek pembuatan abon rebung sampai tahap pengemasan dan catatan pembuatan analisis usahanya.

\section{Metode pengumpulan dan Analisis data}

Metode pengumpulan data dalam pelaksanaan kegiatan adalah dengan wawancara, penyebaran angket (observasi) berisi tentang pemahaman praktek pembuatan abon dan testimoni perhitungan perencanaan usaha. Analisis data menggunakan metode deskriptif kualitatif.

\section{HASIL DAN PEMBAHASAN}

\section{A. Proses Pembuatan Abon Rebung}

a. Pengupasan

Pengupasan dan rebung dilakukan untuk menjaga kebersihan rebung yang akan dijadikan abon. Sebagai bahan baku utama rebung tidak boleh ada kerusakan atau pembusukan pada rebung karena dapat penyebabkan rasa yang tidak sedap pada abon yang sudah diproduksi. Pengupasan rebung cukup dengan membuang bagian kulit rebung yang tersisa dan bagian rebung yang berwarna coklat diakibat kan reaksi respirasi yang disebabkan oleh oksigen. Rebung yang sudah dikupas langsung dibersihkan dengan air bersih dan mengalir. Setelah dicuci rendam rebung dengan sedikit air untuk menjaga rebung tetap basah.

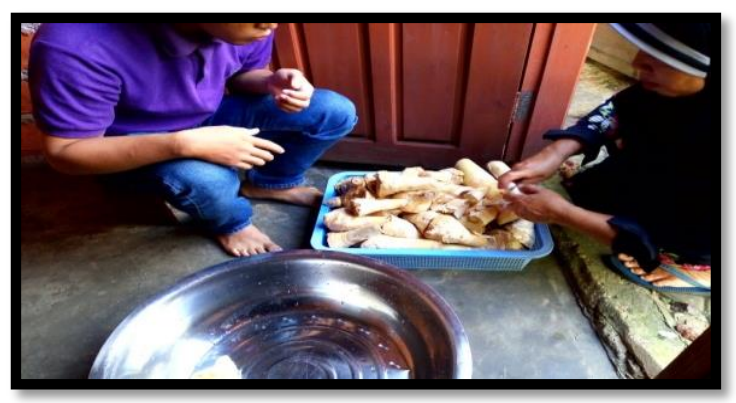

Gambar 1. Pengupasan Bahan Baku Abon Rebung

b. Pemarutan

Pemarutan rebung dilakukan dilakukan setelah pencucian dengan menggunakan alat pemarut mesin dengan bahan bakar bensin sehingga bentuk fisik rebung menjadi lembut seperti kelapa.

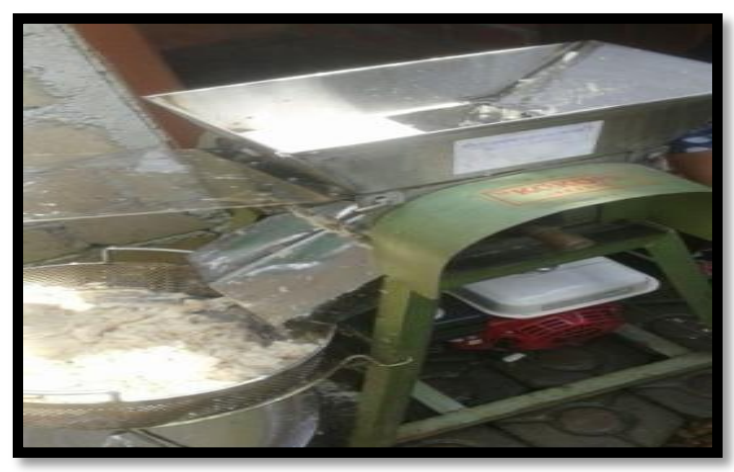

Gambar 2. Pemarutan Rebung Bambu 
c. Penyaringan

Setelah proses pemarutan selesai, rebung yang sudah halus diambil dan dimasukan kedalam kain bersih untuk dimasukan kedalam pres hydraulic. Penggunaan alat pres hydraulic cukup mudah dengan cara memutar gagang hydraulic untuk menekan rebung yang sudah diparut dan mengeluarkan kandungan air yang ada pada rebung.
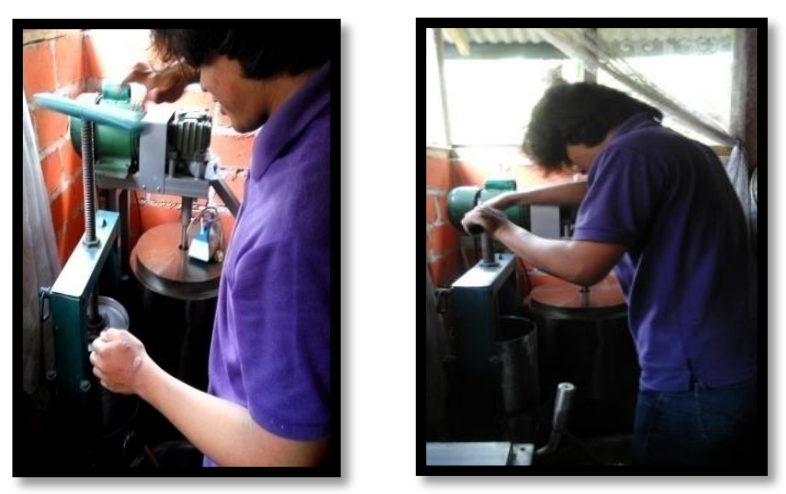

Gambar 3. Penyaringan Rebung Yang Sudah Dihaluskan (Diparut)

d. Persiapan Bumbu

Persiapan bumbu yang akan digunakan dalam pembuatan abon rebung terutama dicuci bersih dengan menggunakan air bersih. Setelah bumbu dibersihkan, beberapa bumbu seperti bawang merah, bawang putih, cabai merah, dan laos dihaluskan menggunakan blender.

e. Penggorengan

Penggorengan didahului dengan penggorengan bumbu halus terlebih dahulu dengan satu liter minyak dan ditambahkan dengan serai, daun salam, dan santan. Setelah bumbu setengah masak dimasukan rebung halus yang sudah dikeringkan dan diaduk rata. Setelah bumbu dan rebung teraduk rata masukkan dua liter minyak tambahan. Penggorengan dilakukan kurang lebih empat jam hingga minyak yang digunakan dalam penggorengan abon kering.

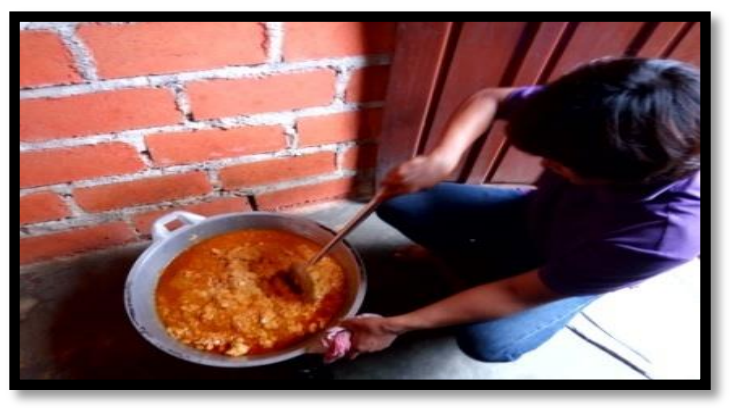

Gambar 4. Penggorengan Abon Rebung

\section{f. Pengeringan}

Pengeringan abon rebung yang sudah melalui proses penggorengan dilakukan dengan menggunakan mesin pengering (spinner). Proses pengeringan merupakan tahap akhir yang sangat menentukan daya tahan produk dan tekstur yang akan dihasilkan. Spinner mengeringkan hampir seluruh kadar minyak yang ada pada abon basah untuk menghasilkan abon kering yang siap dikemas dan dipasarkan.

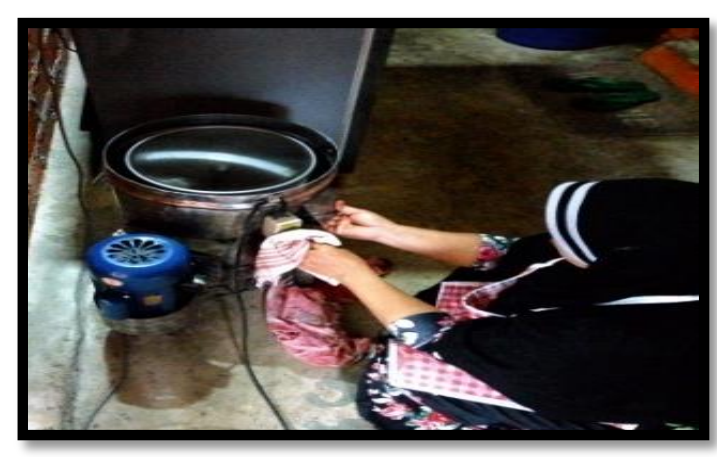

Gambar 5. Pengeringan Abon Rebung

g. Pengemasan dan Pengepresan

Pengemasan abon dan pengepresan produk abon rebung dilakukan setelah abon rebung 
yang dikeringkan menggunakan spinner didinginkan terlebih dahulu agar abon rebung yang berada dalam kemasan tidak menyebabkan bau tidak sedap. Abon dikemas menggunakan plastik alumunium foil. Setelah dimasukan ke dalam kemasan, segera lakukan pengepresan untuk menghindari masuknya udara kedalam kemasan yang dapat menyebabkan penurunan kualitas abon. Dengan perlakuan pengemasan dan pengepresan kemasan dapat membuat abon rebung dapat bertahan selama kurang lebih tiga bulan apabila dismpan dalam ruangan yang terlindung dari sinar matah.

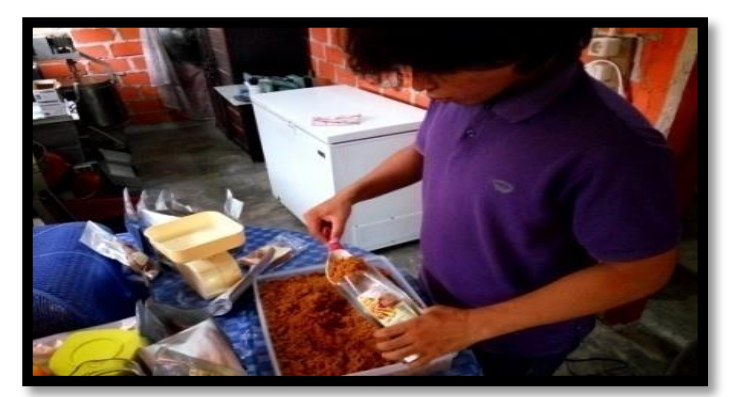

Gambar 6. Pengemasan dan Pengepressan Abon Rebung

\section{B. Analisis Usaha}

\section{Biaya Produksi}

Biaya produksi adalah sejumlah uang yang dikorbankan sebagai modal awal untuk suatu proses produksi usatu usaha (Yulia et al., 2019). Biaya terdiri dari biaya tetap (fixed cost) dan biaya tidak tetap/ biaya variabel (variable cost).

\section{a. Biaya Tetap}

Biaya tetap adalah biaya yang dikeluarkan tanpa mempengaruhi jumlah produksi dalam satu periode. Adapun biaya tetap yang dikeluarkan dalam pembuatan abon rebung di UKM "Raja Abon Makmur Lestari" Kelurahan Air Kepala Tujuh Kota Pangkalpinang adalah:

Tabel 1. Biaya Tetap Produksi Abon PerTahun

\begin{tabular}{lll}
\hline Nama Alat & Jumlah & Penyusutan(Rp) \\
\hline Parut Kelapa & 1 & Rp 35.833,-- \\
Sealer & 1 & Rp 10.000,- \\
Spinner & 1 & Rp 41.666,- \\
Kompor Gas & 1 & Rp 10.000,- \\
Pres Hydraulic & 1 & Rp 38.333,- \\
Wajan Besar & 1 & Rp 6.944,-- \\
Spatula & 1 & Rp 1.458,- \\
Baskom & 2 & Rp 2.500,- \\
Pisau & 2 & Rp 2.083,-- \\
Tabung Gas & 2 & Rp 5.500,- \\
Blender & 1 & Rp 6.250,- \\
Timbangan & 1 & Rp 2.083,- \\
Total Biaya Tetap & & Rp 162.650 \\
\hline
\end{tabular}

Sumber : Analisis Data Primer, 2020

\section{b. Biaya Variabel}

Biaya Variabel adalah biaya yang terus menerus dikeluarkan dalam produksi yang dapat mempengaruhi jumlah atau total produksi. Berikut biaya variabel yang digunakan dalam proses produksi abon rebung:

Tabel 2. Biaya Variabel Produksi Abon Per Tahun

\begin{tabular}{lc}
\hline Nama Bahan & Total Harga (Rp) \\
\hline Rebung Bambu & Rp 3.840.000,- \\
Cabai Merah & Rp 480.000,- \\
Bawang Merah & Rp 177.600,- \\
Bawang Putih & Rp 177.600,- \\
Laos & Rp 144.000,- \\
Daun Salam & Rp 96.000,- \\
Santan & Rp 67.200,- \\
Gula Pasir & Rp 153.600,- \\
Gula Merah & Rp 288.000,- \\
Asam Jawa & Rp 14.423,-- \\
Minyak Goreng & Rp 3.456.000,- \\
\hline
\end{tabular}




\begin{tabular}{lc}
\hline Serai & Rp 38.400,- \\
Garam & $R p ~ 72.000,-$ \\
Kemasan + & Rp 4.320.000,-- \\
Sticker & \\
\hline Total Biaya Variabel & Rp13.324.823,-- \\
\hline Sumber : Analisis Data Primer, 2020
\end{tabular}

Sumber : Analisis Data Primer, 2020

\section{c. Total Biaya}

Total biaya adalah keseluruhan biaya yang digunakan dalam melakukan produksi abon rebung yang didapatkan dari hasil biaya tetap yang dijumlahkan dengan biaya variabel

$\mathrm{TC}=\mathrm{FC}+\mathrm{VC}$

$\mathrm{TC}=\mathrm{Rp} 162.650,-+\mathrm{Rp} 13.324 .823,-$

$\mathrm{TC}=\mathrm{Rp} 13.487 .473,-$

Maka total biaya yang digunakan dalam produksi abon per tahun sebesar $\mathrm{Rp}$ 13.487.473,--

Tabel 3. Total Biaya Produksi Abon Rebung Per Tahun

\begin{tabular}{lll}
\hline No & Uraian & Jumlah \\
\hline $\mathbf{1}$ & Total Biaya Tetap (FC) & Rp 162.650,- \\
$\mathbf{2}$ & $\begin{array}{l}\text { Total Biaya Variabel } \\
\text { (VC) }\end{array}$ & Rp 13.324.823,- \\
\hline & Jumlah Total Biaya & Rp 13.487.473,-- \\
\hline Sumber : Analisis Data Primer, 2020 &
\end{tabular}

\section{Penerimaan}

Penerimaan adalah besarnya uang yang didaptkan dari hasil produksi total yang dikalikan dengan harga persatuan produk. Penerimaan dapat dihitung dengan rumus berikut :

$\mathrm{TR}=2.880 \mathrm{Pcs} \times \mathrm{Rp} 10.000 / \mathrm{Pcs}$

$\mathrm{TR}=\mathrm{Rp} 28.800 .000,-$

Maka diketahui penerimaan yang didapat dari hasil penjualan abon per tahun sebesar Rp 28.800.000,- seperti terlihat pada Tabel 4:
Tabel 4. Penerimaan Penjualan Abon Rebung Per Tahun

\begin{tabular}{llr}
\hline No & Uraian & Jumlah \\
\hline $\mathbf{1}$ & Total Produksi (TP) & 2.880 Pcs \\
$\mathbf{2}$ & Harga Persatuan (P) & Rp 10.000,-- \\
\hline & Total Penerimaan (TR) & Rp 28.800.000,- \\
\hline Sumber : Analisis Data Primer, 2020
\end{tabular}

\section{Pendapatan}

Analisis pendapatan usahatani adalah selisih antara penerimaan dan semua biaya.

$$
\begin{aligned}
& \mathrm{Pd}=\mathrm{TR}-\mathrm{TC} \\
& \mathrm{Pd}=\mathrm{Rp} 28.800 .000,--\mathrm{Rp} 13.487 .473,- \\
& \mathrm{Pd}=\mathrm{Rp} 15.312 .527,-
\end{aligned}
$$

Maka dapat diketahui besarnya pendapatan usaha abon rebung per tahun sebesar $\mathrm{Rp}$ 15.312.527,- seperti terlihat pada tabel 5:

Tabel 5. Total Pendapatan Produksi Abon Per

\begin{tabular}{llr}
\multicolumn{2}{c}{ Tahun } \\
\hline No & Uraian & Jumlah \\
\hline $\mathbf{1}$ & $\begin{array}{l}\text { Total Penerimaan } \\
\text { (TR) }\end{array}$ & $\mathrm{Rp} \mathrm{28.800.000,-}$ \\
$\mathbf{2}$ & Total Biaya (TC) & $\mathrm{Rp} \mathrm{13.487.473,-}$ \\
\hline & Pendapatan (Pd) & $\mathrm{Rp} \mathrm{15.312.527,-}$ \\
\hline Sumber : Analisis Data Primer, 2020 &
\end{tabular}

\section{R/C Ratio}

$\mathrm{R} / \mathrm{C}$ Ratio adalah analisis perbandingan pendapatan dan biaya yang digunakan untuk mengetahui berapa hasil yang diperoleh dari usaha tersebut cukup menguntungkan, merugikan atau impas (Yulia et al., 2020).

$$
\begin{aligned}
\text { R/C Ratio } & =\mathrm{TR} / \mathrm{TC} \\
& =\mathrm{Rp} 28.800 .000,-/ \mathrm{Rp} 13.487 .473,- \\
& =2,13
\end{aligned}
$$

Maka didapatkan nilai R/C Ratio sebesar 2,13 seperti terlihat pada tabel 6 : 
Tabel 6. Analisis R/C Ratio

\begin{tabular}{llr}
\hline No & Uraian & Jumlah \\
\hline $\mathbf{1}$ & $\begin{array}{l}\text { Total Penerimaan } \\
\text { (TR) }\end{array}$ & Rp 28.800.000,- \\
$\mathbf{2}$ & Total Biaya (TC) & Rp 13.487.473,-- \\
\hline & Jumlah & 2,13 \\
\hline
\end{tabular}

Sumber : Analisis Data Primer, 2020

Dengan kriteria yang digunakan adalah jika:

R/C Ratio > 1 = maka usaha menguntungkan

$\mathrm{R} / \mathrm{C}$ Ratio $<1$ = maka usaha merugikan

$\mathrm{R} / \mathrm{C}$ Ratio $=1=$ maka usaha impas

Maka usaha abon rebung dapat dikategorikan menguntungkan karena hasil dari analisis R/C Ratio Didapatkan dengan nilai R/C Ratio > 1 atau sama dengan 2,13.

\section{Break Even Point (BEP)}

Break Even Point (BEP) untuk mengetahui pada kondisi mana perusahaan tidak merasakan kerugian atau dengan kata lain total biaya pembuatan abon rebung sama dengan total penjualan abon rebung sehingga tidak ada laba dan tidak ada kerugian (Yulia et al., 2020). Hal ini bisa terjadi apabila perusahaan di dalam operasinya menggunakan biaya tetap dan biaya variabel, dan volume penjualan hanya cukup menutup biaya tetap dan biaya variabel.

$$
\begin{aligned}
\text { a. BEP Penerimaan } & =\frac{162.650}{1-\frac{13.324 .823}{28.800 .000}} \\
& =\frac{162.650}{1-0,46} \\
& =162.649,54 \\
\text { b. BEP Produk } & =\frac{162.650}{10.000-4.626,67} \\
& =\frac{162.650}{5.373,33}=30.26
\end{aligned}
$$

c. $\quad$ BEP Harga $=\frac{13.487 .473}{2.880}$

$$
=4.683,15
$$

Tabel 7. Analisis Break Even Point (BEP)

\begin{tabular}{clr}
\hline No & Uraian & Jumlah \\
\hline 1 & BEP Penerimaan & Rp 162.649,54 \\
2 & BEP Produk & $30,26 \mathrm{pcs}$ \\
3 & BEP Harga & Rp 4.683,15 \\
\hline \multicolumn{2}{l}{ Sumber: Analisis Data Primer, 2020 }
\end{tabular}

\section{SIMPULAN}

Kesimpulan dari pelaksanaan kegiatan pengabdian ini adalah pemilik usaha abon rebung sudah terampil dalam proses produksi abon rebung, mahir dalam perhitungan analisis usaha bisnis dan kreatif dalam membuat produk usaha abon rebung.

\section{DAFTAR PUSTAKA}

Arda, G., Kencana, P. K. D., Gunadnya, I., \& Yulianti, N. L. (2016). Model Pengeringan Lapisan Tipis Rebung Bambu "Tabah" (Gigantochloa nigrociliata KURZ). Rona Teknik Pertanian, 9(1), 62-73. https://doi.org/10.17969/rtp.v9i1.4408

Howard Patty, R., Semadi Antara, N., \& Arnata, I. (2014). Pengaruh Bagian Rebung dan Perlakuan Pendahuluan Terhadap Karakteristik Tepung dari Rebung Bambu Tabah (Gigantochloa nigrociliata BUSE KURZ). Jurnal Rekayasa Dan Manajemen Agroindustri, 2(2), 87-98.

Jaka S Sumardjo, W. A. D. (2004). Teori dan Praktik Kemitraan Agribisnis (88th ed.). Penebar Swadaya.

Rachmadi, A. T. (2011). Pemanfaatan Fermentasi Rebung Untuk Bahan Suplemen Pangan Dan Tepung Serat. Jurnal Riset Industri Hasil Hutan, 3(1), 37. https://doi.org/10.24111/jrihh.v3i1.1187

Wijatno, S. (2009). Pengantar Enterprenuership. PT. Grasindo.

Yulia, Y., Bahtera, N. I., \& Evahelda, E. (2019a). a Swot Analysis on the Implementation of the Marketing Strategy : a Case Study in the Raja Abon Makmur Lestari , Pangkalpinang City ,. 
68 Pendampingan Analisis Usaha Pembuatan Abon Rebung di UKM "Raja Abon Makmur Lestari" Kelurahan Air Kepala Tujuh Kota Pangkal Pinang - Yulia

DOI: https://doi.org/10.31004/abdidas.v2i1.209

International Journal of Business and Economy, 1(2), 26-32.

Yulia, Y., Bahtera, N. I., \& Evahelda, E. (2019b). SWOT Application in Marketing Strategy for Chicken Egg Shredded in UKM "Raja Abon Makmur Lestari" in Pangkalpinang City. International Journal of Advances in Social and Economics, 1(2), 73. https://doi.org/10.33122/ijase.v1i2.43

Yulia, Y., Bahtera, N. I., Evahelda, E., Hayati, L., \& Bahtera, N. T. (2020). Business Development Strategy Using Business Model Canvas Approach. Jurnal Muara Ilmu Ekonomi Dan Bisnis, 4(1), 106. https://doi.org/10.24912/jmieb.v4i1.7563

Yulia, Y., Putri, A. K., \& Purwasih, R. (2019a). Pelatihan Pendampingan Usaha Produksi Ukm "Raja Abon Makmur Lestari" Berbasis Marketing Strategy. Jurnal Pengabdian Kepada Masyarakat UBB, 6(2), 6-11.

Yulia, Y., Putri, A. K., \& Purwasih, R. (2019b). Pendampingan Usaha Produksi Ukm Raja Abon Makmur Lestari Berbasis Marketing Strategy. Journal of Chemical Information and Modeling, 01(01), 1689-1699. 